\title{
Evaluating the Early Impact of the COVID-19 Pandemic on Sports Surgery Fellowship Education
}

Peter R. Swiatek ${ }^{1}$, Joseph Weiner ${ }^{1}$, Bejan A. Alvandi ${ }^{1}$, Daniel Johnson ${ }^{1}$, Bennet Butler ${ }^{1}$, Vehniah Tjong ${ }^{1}$ , Michael A. Terry ${ }^{1}$

1. Department of Orthopaedic Surgery, Northwestern University Feinberg School of Medicine, Chicago, USA

Corresponding author: Bejan A. Alvandi, bejan.alvandi@gmail.com

\section{Abstract \\ Purpose}

The COVID-19 pandemic forced many hospitals to cancel elective surgeries to minimize the risk of viral transmission and ensure the availability of vital health resources. The unintended consequences of this action on the education and training of orthopaedic sports surgeons are unknown. The purpose of this study is to measure the impact of COVID-19 on orthopaedic sports surgery fellows, their education and training, and their readiness for practice.

\section{Methods}

A comprehensive survey was created and distributed to all U.S. fellows and fellowship directors registered with the American Orthopaedic Society for Sports Medicine. Responses were collected between April 22, 2020, and May 5, 2020.

\section{Results}

Fifty-one sports fellows and twenty-nine sports fellowship directors completed the survey. Over $80.4 \%$ of fellows reported a greater than $50 \%$ decrease in the case volume since the cessation of elective cases. Average hours worked per week decreased by $58.2 \%$ during the pandemic. Fellows reported completing an average of $324.6 \pm 97.4$ cases prior to the COVID-19 crisis and $86.0 \%$ expected to complete at least $11 \%$ to $25 \%$ fewer cases by graduation compared to previous fellows. $87.5 \%$ of fellows were not concerned about their ability to complete their fellowship training but more than one-third of fellows voiced concerns to their fellowship directors regarding their readiness for independent practice. Fellowship directors were generally not concerned that COVID-19 would prevent their fellows from completing the fellowship. At least $54.2 \%$ are somewhat concerned about the impact of COVID-19 on their future job opportunities.

\section{Conclusions}

Review began 01/05/2021 Review ended 01/16/2021 Published 01/27/2021

\section{(๑) Copyright 2021}

Swiatek et al. This is an open access article distributed under the terms of the Creative Commons Attribution License CC-BY 4.0., which permits unrestricted use, distribution, and reproduction in any medium, provided the original author and source are credited.
The COVID-19 pandemic has universally affected work hours and case volume of sports fellows. Nevertheless, most sports fellows feel prepared to enter practice and are generally supported by the confidence of their fellowship directors. The results of this survey emphasize the importance of the fellowship year in sports training and highlight the future of online education and simulation as useful adjuncts.

Categories: Medical Education, Orthopedics

Keywords: sports surgery, fellowship, education, covid-19, coronavirus, orthopaedic surgery

\section{Introduction}

The COVID-19 pandemic has emerged as a disastrous global health crisis [1,2]. Patients infected with COVID-19 placed an enormous strain on health care systems around the world [3]. Meeting these requirements in severely affected regions has proven demanding [4]. To address the transmission risk and help reallocate critical resources, many United States hospitals and surgery centers postponed elective surgeries in March 2020 [5].

Despite the interruption of elective surgery, orthopaedic departments across the United States have continued to provide urgent and emergent surgical services [6]. Although numerous editorials and societylevel guidelines have been published to address the impact of COVID-19 on orthopaedic care [7-9], little is known about the effects of the pandemic on sports fellowship education.

Over the past several decades, fellowship training has become increasingly popular among orthopaedic surgeons [10]. The sports surgery fellowship is an intensive one-year of experiential learning during which 
trainees improve technical skills and gain valuable knowledge critical for diagnosing and managing sportsrelated conditions. Given the reported educational value of fellowship experience for sports surgery trainees $[11,12]$ and the universal effect of COVID-19 on reducing elective orthopaedic surgery volume, we sought (1) to evaluate the impact of COVID-19 on sports fellow training and education, (2) to measure the effect of the pandemic on sports fellows' readiness to enter practice, and (3) to discuss how COVID-19 has highlighted opportunities for improvement and innovation in sports fellow education.

\section{Materials And Methods \\ Survey strategy and content}

A team of board-certified orthopaedic sports surgeons and trainees designed the survey for current sports surgery fellows and fellowship directors during the 2019-2020 academic year. Questions were chosen for inclusion in the survey via the Delphi technique [13], in which attending-level surgeons reached consensus after several rounds of discussion. Two questionnaires were developed created using SurveyMonkey (San Mateo, California, USA) to target both sports surgery fellows and fellowship directors.

The survey targeted data such as geographic location, the timeline of elective surgery cancellation, impact on case-mix and volume, the effect on education, training, and job opportunities. Geographic location was broken down by region as defined by the United States Census Bureau [14]. The range of concern was measured using a Likert scale from one to five ( 1 = "non-concerned" to 5 = "extremely concerned").

\section{Survey circulation}

The 36-question fellows' questionnaire and 34-question fellowship directors' questionnaires were circulated in English via email to American Orthopaedic Society for Sports Medicine (AOSSM) fellows ( $\mathrm{n}=215$ ) and fellowship directors $(n=90)$. The survey remained open for two weeks (April 22, 2020 - May 5, 2020). Prior to the start of the survey, participants were informed that their contribution was entirely voluntary and that their results would be kept confidential and only analyzed and presented in aggregate in peer-reviewed journals, social media, or other web-based media outlets.

\section{Statistical analysis}

Data were collected from individual respondents, aggregated in Microsoft Excel (Redmond, Washington, USA), and analyzed. Means and percentages were calculated for rank-order and discrete data, respectively. Differences in continuous variables were assessed using student t-tests and differences in discrete variables were calculated using chi-square tests where applicable. Additionally, a univariate analysis was conducted to determine the impact of key independent variables, including fellowship regions/location, fellowship setting (i.e., urban, suburban, or rural), and the number of fellows in the program, on fellows' overall concern regarding readiness to enter practice and their deployment to non-sports-related patient care roles. All analyses were executed using XLSTAT (Addinsoft, Paris, France). Differences were determined to be significant for $\mathrm{p}<0.05$.

\section{Results}

A total of 51 sports surgery fellows and 29 sports fellowship directors completed the survey, representing response rates of $23.7 \%$ and $32.2 \%$, respectively. The majority of fellows $(38 / 51,74.5 \%)$ and half of the fellowship directors $(15 / 29,51.7 \%)$ reported training in urban locations. Most of the fellows represented programs with three or more fellows $(28 / 51,54.9 \%)$ whereas most of the fellowship directors represented programs with two or fewer fellows (19/29, 65.5\%; Table 1$)$. 


\section{Cureus}

\begin{tabular}{|c|c|c|c|c|}
\hline & \multicolumn{2}{|c|}{ Fellows } & \multicolumn{2}{|c|}{ Fellowship directors } \\
\hline & $\#$ & $\%$ & \# & $\%$ \\
\hline \multicolumn{5}{|l|}{ Fellowship region } \\
\hline Northeast & 16 & 31.4 & 6 & 20.7 \\
\hline Midwest & 13 & 25.5 & 8 & 27.6 \\
\hline South & 11 & 21.6 & 7 & 24.1 \\
\hline West & 11 & 21.6 & 8 & 27.6 \\
\hline \multicolumn{5}{|l|}{ Fellowship setting } \\
\hline Urban & 38 & 74.5 & 15 & 51.7 \\
\hline Suburban & 11 & 21.6 & 13 & 44.8 \\
\hline Rural & 2 & 3.9 & 1 & 3.5 \\
\hline \multicolumn{5}{|c|}{ Number of fellows in the program } \\
\hline 1 & 7 & 13.7 & 9 & 31 \\
\hline 2 & 16 & 31.4 & 10 & 34.5 \\
\hline 3 & 7 & 13.7 & 4 & 13.8 \\
\hline 4 & 5 & 9.8 & 3 & 10.3 \\
\hline 5 & 8 & 15.7 & 3 & 10.3 \\
\hline 6 & 3 & 5.9 & 0 & 0 \\
\hline 7 & 1 & 2 & 0 & 0 \\
\hline 8 & 2 & 3.9 & 0 & 0 \\
\hline 9 & 2 & 3.9 & 0 & 0 \\
\hline Iotal respondents & 51 & 100 & 29 & 100 \\
\hline
\end{tabular}

\section{TABLE 1: Survey respondent demographics}

\section{Impact of COVID-19 and program response}

All sports fellowship programs began enacting precautionary measures for COVID-19 prior to April 2020. The majority of fellows reported taking precautions between March 15 and 31, 2020 (37/51, 72.6\%) compared to most directors, who reported taking precautions prior to March 15, 2020 (16/29, 55.2\%). All respondents, with the exception of two sports fellows, reported cancellation of elective cases at the time of the survey. Most fellows $(41 / 51,80.4 \%$ ) saw a decrease in the case volume by more than $50 \%$. Prior to cessation of elective cases, sports fellows worked an average of $51.0 \pm 11.3$ hours per week. Afterwards the COVID-19 shutdown, mean hours worked per week dropped to $22.9 \pm 15.9$ hours, representing a decrease of $28.2 \pm 15.9$ mean hours per week $(<0.0001)$. Eleven of 51 fellows $(21.6 \%)$ reported being deployed to non-sports surgery roles, including four fellows who were assigned to manage COVID-19 units. In a univariate analysis, there was no difference in rates of re-deployment to non-sports surgery roles based upon fellowship region $(\mathrm{p}=0.57)$, fellowship setting $(\mathrm{p}=0.7)$, and the number of fellows in a program $(\mathrm{n}=0.55)$. Attending staff, trainees, or ancillary staff tested positive for COVID-19 at 48\% (24/50) of fellows' programs. Most (45/51, 90.0\%) were satisfied with current COVID-19 precautions and discussed the impact of COVID-19 on training at least weekly (36/51, 75.0\%; Table 2$)$.

Fellows

\#/Mean $\% / \pm$ SD

\section{Fellowship directors}

\#/Mean $\% / \pm$ SD 


\section{Cureus}

\begin{tabular}{|c|c|c|c|c|c|}
\hline Prior to March 1 & 0 & 0.0 & Prior to March 1 & 1 & 3.5 \\
\hline March 1-14 & 14 & 27.5 & March 1-14 & 15 & 51.7 \\
\hline March 15-31 & 37 & 72.6 & March 15-31 & 13 & 44.8 \\
\hline April 1 to present & 0 & 0.0 & April 1 to present & 0 & 0.0 \\
\hline No changes made & 0 & 0.0 & No changes made & 0 & 0.0 \\
\hline Elective cases cancelled & & & Elective cases cancelled & & \\
\hline Yes & 49 & 96.1 & Yes & 29 & 100.0 \\
\hline No & 2 & 3.9 & No & 0 & 0.0 \\
\hline Decrease in overall institution case volume & 51 & & Decrease in overall institution case volume & & \\
\hline $0-25 \%$ & 7 & 13.7 & $0-25 \%$ & 2 & 6.9 \\
\hline $26-50 \%$ & 3 & 5.9 & $26-50 \%$ & 2 & 6.9 \\
\hline $51-75 \%$ & 8 & 15.7 & $51-75 \%$ & 3 & 10.3 \\
\hline$>75 \%$ & 33 & 64.7 & $>75 \%$ & 22 & 75.9 \\
\hline $\begin{array}{l}\text { Mean hours worked per week pre-COVID } \\
(n=51)\end{array}$ & 51.0 & 11.3 & $\begin{array}{l}\text { Mean hours fellows worked per week pre-COVID } \\
(\mathrm{n}=29)\end{array}$ & 51.1 & 11.5 \\
\hline $\begin{array}{l}\text { Mean hours worked per week post-COVID } \\
(n=50)\end{array}$ & 22.9 & 15.9 & $\begin{array}{l}\text { Mean hours fellows worked per week post-COVID } \\
(\mathrm{n}=29)\end{array}$ & 21.3 & 12.9 \\
\hline Assisting with non-sports-related care & & & Fellows assisting with non-sports-related care & & \\
\hline Yes & 11 & 21.6 & Yes & 7 & 24.1 \\
\hline No & 40 & 78.4 & No & 22 & 75.8 \\
\hline Satisfied with current precautions ${ }^{a}$ & & & Satisfied with current precautions ${ }^{c}$ & & \\
\hline Yes & 45 & 90.0 & Yes & 23 & 95.8 \\
\hline No & 5 & 10.0 & No & 1 & 4.2 \\
\hline Frequency of COVID communication with fel & lowshi & irector & Frequency of COVID communication with fellow ${ }^{d}$ & & \\
\hline Never & 0 & 0.0 & Never & 0 & 0.0 \\
\hline Bi-weekly & 12 & 25.0 & Bi-weekly & 6 & 26.1 \\
\hline Weekly & 31 & 64.6 & Weekly & 7 & 30.4 \\
\hline Daily & 4 & 8.3 & Daily & 10 & 43.5 \\
\hline Multiple times a day & 1 & 2.1 & Multiple times a day & 0 & 2.1 \\
\hline Staff testing positive for COVID ${ }^{a}$ & & & Staff positive for COVID ${ }^{C}$ & & \\
\hline Attending staff & 9 & 18.0 & Attending staff & 3 & 12.5 \\
\hline Fellow/resident & 8 & 16.0 & Fellow/resident & 2 & 8.3 \\
\hline Ancillary staff & 7 & 14.0 & Ancillary staff & 3 & 12.5 \\
\hline None & 28 & 56.0 & None & 16 & 66.7 \\
\hline \multirow[t]{6}{*}{ Prefer not to answer } & 9 & 18.0 & Prefer not to answer & 2 & 8.3 \\
\hline & & & Decision making for non-emergent surgeries ${ }^{C}$ & & \\
\hline & & & Attending decision & 7 & 29.2 \\
\hline & & & Service guidelines & 5 & 20.8 \\
\hline & & & Hospital/OR guidelines & 14 & 58.3 \\
\hline & & & State guidelines & 8 & 33.3 \\
\hline
\end{tabular}




\section{Cureus}

\section{TABLE 2: COVID-19 response}

The majority of fellowship directors $(25 / 29,86.2 \%)$ reported a decrease in the case volume by more than $50 \%$. Their fellows worked an average of $51.0 \pm 11.5$ hours prior to the COVID-19 shutdown and subsequently worked $21.3 \pm 12.9$ hours during the height of the pandemic, which represented a $29.8 \pm 13.1$ hour decrease $(\mathrm{p}<0.0001)$. Seven directors reported that their fellows were re-deployed to non-sports surgery roles, including orthopaedic urgent care and trauma services. Attending staff, trainees, or ancillary staff tested positive at $33.3 \%$ of directors' programs. Nearly, all directors were satisfied with current precautions taken at their institution $(23 / 24,95.8 \%)$. According to fellowship directors, the distinction between "emergent/urgent" cases versus "non-emergent" cases was primarily defined by hospital-specific guidelines (14/29, 58.3\%) and state guidelines (8/24, 33.3\%). Only nine fellowship directors used a standardized scoring system to determine case priority (9/24, 37.5\%).

\section{Case variety and volume}

On average, fellows completed $324.6 \pm 97.4$ cases prior to the COVID-19 shutdown, and the majority (43/51, $86.0 \%$ ) expected to complete at least $11 \%$ to $25 \%$ fewer cases by graduation compared to fellows from the previous years. Nearly, all fellowship directors reported similar expectations (23/24, 95.8\%). Fellows reported distal biceps tendon repair (33/51, 66.0\%), knee extensor tendon repair (37/51,74.0\%), and shoulder arthroscopy $(32 / 51,64.0 \%)$ as the most common sports cases still occurring at their institutions. Their responses mimic those of fellowship directors whose programs were still surgically treating patients with elbow tendon repairs (18/24, 75.0\%), knee extensor tendon repairs (22/24, 91.7\%), and shoulder arthroscopy (11/24, 45.8\%; Figure 1). Fellows (29/51, 58.0\%) and fellowship directors (10/24, 41.7\%) also reported that ligamentous reconstructions after knee injuries were occasionally occurring at their institutions (Table 3).

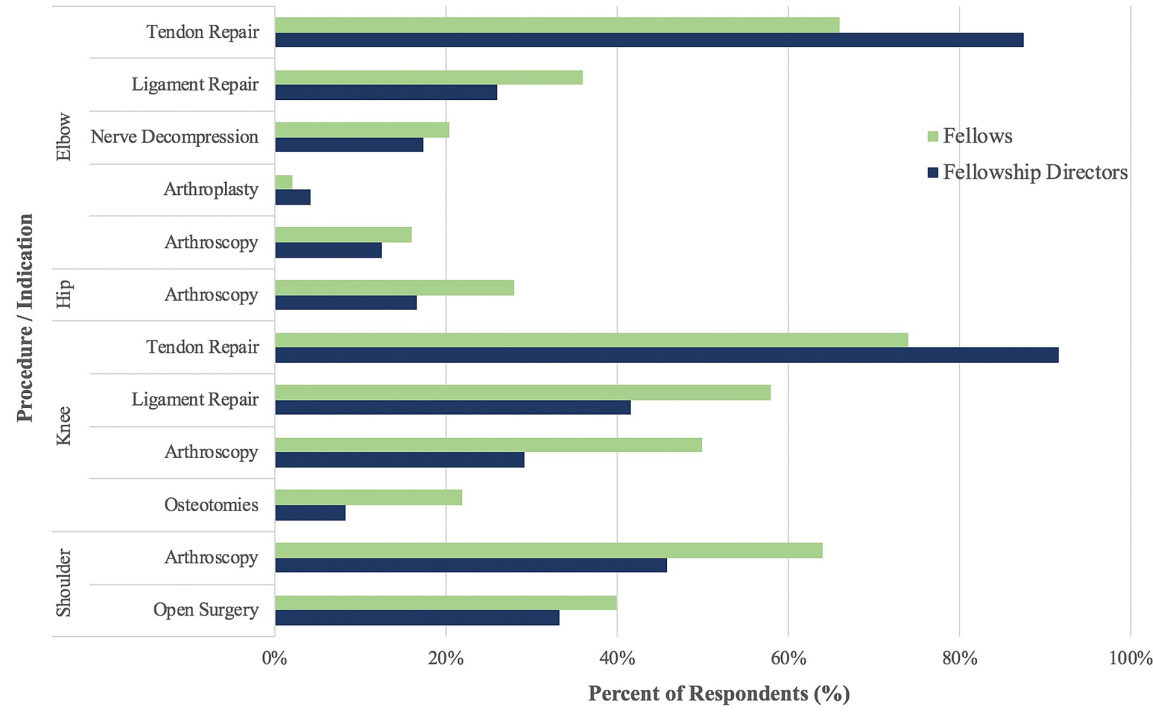

FIGURE 1: Case-mix of sports cases occurring during the COVID-19 pandemic. The most common elbow, hip, knee, and shoulder cases occurring during the cessation of elective cases. All numbers are selfreported by sports fellows and fellowship directors. 


\section{Cureus}

\begin{tabular}{|c|c|c|c|c|}
\hline & \multicolumn{2}{|c|}{ Fellows $(n=51)$} & \multicolumn{2}{|c|}{ Directors $(\mathrm{n}=24)$} \\
\hline & \#/Mean & $\% / \pm$ SD & \#/Mean & $\% / \pm \mathrm{SD}$ \\
\hline Cases personally completed prior to COVID-19 Shutdown & 324.6 & 97.4 & $\mathrm{n} / \mathrm{a}$ & $\mathrm{n} / \mathrm{a}$ \\
\hline \multicolumn{5}{|l|}{ Estimated percent decrease in yearly case volume vs last year } \\
\hline $0-10 \%$ & 7 & 14 & 1 & 4.2 \\
\hline $11-25 \%$ & 35 & 70 & 18 & 75 \\
\hline $26-50 \%$ & 7 & 14 & 5 & 20.8 \\
\hline$>50 \%$ & 1 & 2 & 0 & 0 \\
\hline \multicolumn{5}{|l|}{ Elbow cases still occurring } \\
\hline Arthroscopy & 8 & 16 & 3 & 12.5 \\
\hline Tendon repair & 33 & 66 & 21 & 87.5 \\
\hline Ligament repair & 18 & 36 & 6 & 26.1 \\
\hline Arthroplasty & 1 & 2 & 1 & 4.2 \\
\hline Nerve decompression & 10 & 20.4 & 4 & 17.4 \\
\hline \multicolumn{5}{|l|}{ Other } \\
\hline \multicolumn{5}{|l|}{ Hip cases still occurring } \\
\hline Arthroscopy & 14 & 28 & 4 & 16.7 \\
\hline \multicolumn{5}{|l|}{ Other } \\
\hline \multicolumn{5}{|l|}{ Knee cases still occurring } \\
\hline Ligamentous reconstruction & 29 & 58 & 10 & 41.7 \\
\hline Arthroscopy & 25 & 50 & 7 & 29.2 \\
\hline Tendon repair & 37 & 74 & 22 & 91.7 \\
\hline Osteotomies & 11 & 22 & 2 & 8.3 \\
\hline \multicolumn{5}{|l|}{ Other } \\
\hline \multicolumn{5}{|l|}{ Shoulder cases still occurring } \\
\hline Arthroscopy & 32 & 64 & 11 & 45.8 \\
\hline Open surgery & 20 & 40 & 8 & 33.3 \\
\hline Arthroplasty & 13 & 26 & 4 & 17.4 \\
\hline Other & & & & \\
\hline
\end{tabular}

\section{TABLE 3: Case volume/mix}

\section{Readiness for practice}

Fellows were generally not concerned that COVID-19 would limit their ability to complete fellowship (42/48, $87.5 \%)$. Prior to the pandemic, fellows expressed very low concern regarding their ability to enter practice after fellowships $(1.54 \pm 0.8,1=$ not concerned, $5=$ =xtremely concerned). There was a trend toward increased concern during the shutdown of elective cases, but the increase did not reach statistical significance $(1.77 \pm$ 1.0 , D $0.23 \pm 0.4, p=0.204$; Figure 2). Fellows believed that they would be ready to begin practice if elective case began in May (48/48, 100\%), June (46/48, 95.8\%), or July (36/48, $75.0 \%)$, and more than one-third of fellows voiced concerns about their fellowship directors regarding their preparedness to start practice (Table 4). In a univariate analysis, levels of self-reported concern and incidence of reporting concern to the fellowship director were not associated with fellowship region $(\mathrm{p}=0.18$ and $\mathrm{p}=0.06$ ), fellowship setting $(\mathrm{p}=0.3$ and $\mathrm{p}=0.06)$, or the number of fellows in a program (0.34 and 0.55$)$. 


\section{Cureus}

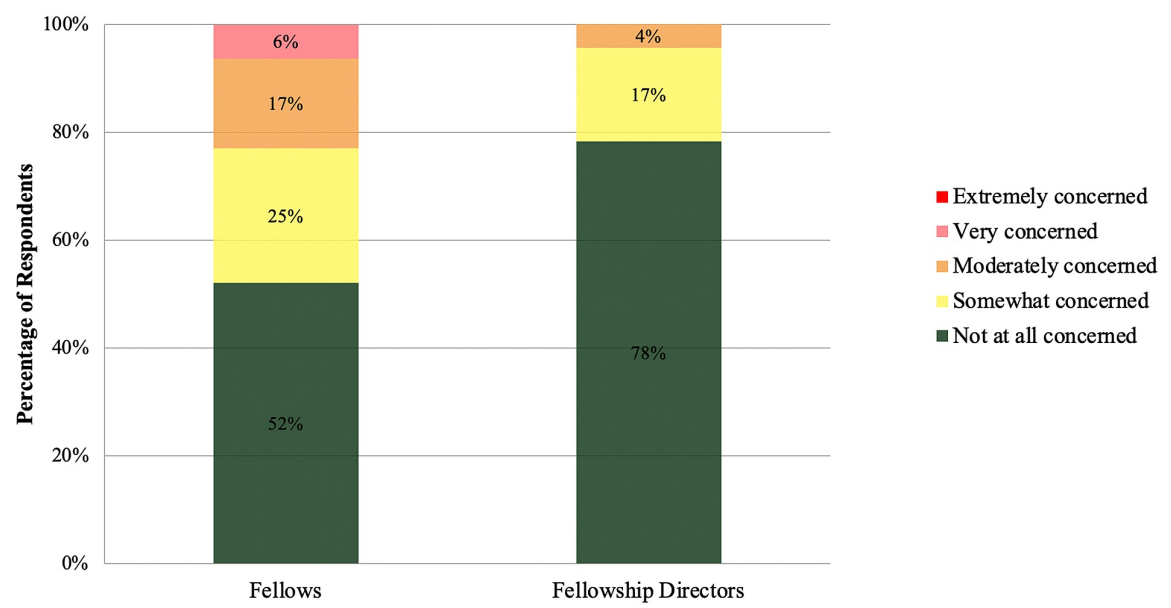

FIGURE 2: Self-reported concern regarding fellow readiness for practice. Fellow and fellowship director self-reported concern regarding fellow preparedness to begin practice after fellowship graduations.

Fellow $(n=48)$ \#/Mean \%/

Will COVID limit fellowship completion?

Yes
No
Concern regarding the ability to enter practice pre-
COVID (1-not concerned, 5 -extremely concerned)

Concern regarding the ability to enter practice post-COVID (1-not concerned, 5-extremely concerned)

Prepared to start practice if elective cases resume in:

Fellowship director $(n=23)$

SD

Will COVID prevent your fellow from graduating?

$\begin{array}{lllll}6 & 12.5 & \text { Yes } & 4 & 17.4 \\ 42 & 87.5 & \text { No } & 19 & 82.6\end{array}$

Concern regarding the ability to enter practice 0.8 pre-COVID (1-not concerned, 5-extremely $1.08 \quad 0.3$ concerned)

Concern regarding the ability to enter practice $\begin{array}{lllll}1.77 & 1 & \text { post-COVID (1-not concerned, 5-extremely } & 1.24 & 0.5\end{array}$ concerned)

Fellow prepared to start practice if elective cases resume in:

\begin{tabular}{|llllll|} 
May & 48 & 100 & May & 21 & 91.3 \\
\hline June & 46 & 95.8 & June & 22 & 95.6 \\
\hline $\begin{array}{l}\text { July } \\
\begin{array}{l}\text { Voiced concern to fellowship director about } \\
\text { preparedness }\end{array}\end{array}$ & 36 & 75 & July & 18 & 78.3 \\
\hline
\end{tabular}

TABLE 4: Fellow preparedness vs fellowship director assessment of preparedness

Similar to fellows, fellowship directors were generally confident that COVID-19 would not prevent their fellows from graduating (19/23, 82.6\%). Prior to the COVID-19 shutdown, fellowship directors were not concerned regarding their fellows' ability to start practice after graduation $(1.08 \pm 0.3,1=$ not concerned, $5=$ extremely concerned). There was a trend toward increased concern during the COVID-19 shutdown, but this did not reach statistical significance $(1.24 \pm 0.5, \mathrm{D} 0.16 \pm 0.4, \mathrm{p}=0.183)$. Fellowship directors believed that their fellows would be ready to begin practice if elective cases began in May (21/24, 91.3\%), June (22/24, 95.6\%), or July (18/24, 78.3\%). Despite their relatively low concern, $35 \%$ of fellowship directors $(8 / 23)$ reported that their fellows voiced concerns to them regarding readiness to start practice after fellowship.

\section{Education and job opportunities}




\section{Cureus}

Fellows and fellowship directors reported changes to their sports curriculum, with the transition to a digital or virtual curriculum for didactics being most commonly reported by fellows (42/48, $87.5 \%$ ) and directors $(20 / 23,87.0 \%)$. Most sports fellows were in contact with other sports fellows during the pandemic (34/48, $70.8 \%$ ), but many did not feel connected to other fellows (20/48, 41.7\%). Similarly, fellowship directors were in contact with other directors regarding fellow education (12/23, 52.2.\%); however, $30.4 \%$ of directors felt disconnected from other directors $(7 / 23)$. The majority of fellows $(41 / 48,85.4 \%)$ reported having jobs arranged prior to the start of the COVID-19 pandemic and most fellows $(26 / 48,54.2 \%)$ are at least somewhat concerned that their future job may be affected by the COVID-19 (Table 5).

\begin{tabular}{|c|c|c|c|c|c|}
\hline \multicolumn{3}{|l|}{ Fellow $(n=48)$} & \multicolumn{3}{|l|}{ Fellowship director $(\mathrm{n}=23$ ) } \\
\hline & $\#$ & $\%$ & & \# & $\%$ \\
\hline \multicolumn{3}{|l|}{ Changes to the education curriculum } & \multicolumn{3}{|l|}{ Changes to the fellow education curriculum } \\
\hline Met less frequently (in-person or virtually) & 10 & 20.8 & Met less frequently (in-person or virtually) & 3 & 13 \\
\hline Met more frequently (in-person or virtually) & 20 & 41.7 & Met more frequently (in-person or virtually) & 6 & 26.1 \\
\hline $\begin{array}{l}\text { Changed to a digital/virtual curriculum for didactic } \\
\text { education }\end{array}$ & 42 & 87.5 & $\begin{array}{l}\text { Changed to a digital/virtual curriculum for didactic } \\
\text { education }\end{array}$ & 20 & 87 \\
\hline $\begin{array}{l}\text { Already was using a digital/virtual curriculum for } \\
\text { didactic education }\end{array}$ & 0 & 0 & $\begin{array}{l}\text { Already was using a digital/virtual curriculum for } \\
\text { didactic education }\end{array}$ & 1 & 4.4 \\
\hline \multicolumn{3}{|l|}{ Contact with other sports fellows during the pandemic } & \multicolumn{3}{|c|}{ Contact with other fellowship directors about fellow education } \\
\hline Yes & 34 & 70.8 & Yes & 12 & 52.2 \\
\hline No & 14 & 29.2 & No & 11 & 47.8 \\
\hline \multicolumn{3}{|l|}{ Felt connected to other fellows during the pandemic } & \multicolumn{3}{|c|}{ Felt connected to other fellowship directors during the pandemic } \\
\hline Yes & 28 & 58.3 & Yes & 16 & 69.6 \\
\hline No & 20 & 41.7 & No & 7 & 30.4 \\
\hline \multicolumn{6}{|l|}{ Job arranged prior to COVID } \\
\hline Verbal commitment & 8 & 16.7 & & & \\
\hline Received offer letter but had not signed & 7 & 14.6 & & & \\
\hline Signed contract & 26 & 54.2 & & & \\
\hline No & 7 & 14.6 & & & \\
\hline Cancelled job interviews & 9 & 22.9 & & & \\
\hline \multicolumn{6}{|l|}{ Concern regarding job start date or rescinding of job offer } \\
\hline Very concerned & 2 & 4.2 & & & \\
\hline Somewhat concerned & 24 & 50 & & & \\
\hline Not concerned & 16 & 33.3 & & & \\
\hline I do not have a job lined up yet & 6 & 12.5 & & & \\
\hline
\end{tabular}

TABLE 5: Fellow education and employment opportunities

\section{Discussion}

The COVID-19 pandemic is not the first global health crisis to challenge U.S. health care systems. During the 20th century, there were several pandemics: the H1N1 Spanish flu of 1918, the H2N2 Asian flu of 1957, and the H3N2 Hong Kong flu of 1968 [15]. However, the COVID-19 pandemic crisis is the first to impact the U.S. since the expansion of orthopaedic fellowship education. Given that $90 \%$ of orthopaedic surgery residents pursue a post-graduate fellowship to refine their clinical acumen and surgical skill set prior to entering practice, the impact of COVID-19 on training is undoubtedly anxiety-provoking for many, including sports surgery fellows. Several recent editorials have discussed the impact of COVID-19 on orthopaedic trainee education $[9,16,17]$. For example, a group of spine surgery fellows in New York City 
described their experience of being re-deployed to non-spine-related patient care services and the impact the cancellation of all elective cases had on their training and educational objectives [17]. No study to date, however, has measured the impact of COVID-19 on sports surgery fellow training and education. We analyzed input from the AOSSM academic community, specifically 51 sports surgery fellows and 29 sports fellowship directors, to better understand the state of sports surgery training during the COVID-19 pandemic, to assess the effect of the pandemic on fellows' preparedness for practice, and to discuss potential opportunities to improve sports surgery fellow education.

Our survey revealed that nearly all sports surgery programs saw a complete cessation of elective cases and a more than 50\% work hour reduction beginning in mid-March 2020. Most fellows and fellowship directors anticipated that each fellow would graduate with $11 \%$ to $25 \%$ fewer cases compared to previous years' trainees. To continue sports education during the COVID-19 shutdown, many programs transitioned their curriculum to virtual or web-based platforms similar to certain spine fellowship [17] and orthopaedic residency [9] programs. Authors from one orthopaedic residency program in New York City describe how their program was able to continue their standard conference schedule virtually while expanding educational opportunities to include presentations from other local programs and industry, lectures from American Hip and Knee Society FOCAL curriculum, and virtual reality (VR) experiences via headsets for residents at home [18]. Needless to say, COVID-19 has ignited the topic of online education for orthopaedic residents and fellows. Several authors even predict that online education may become a part of the "new normal” for orthopaedic resident and fellow education [16-18]. At this stage, however, the rapid rise in online education offerings and resources seems to be fragmented and somewhat unstructured. Moreover, hands-on experience is still widely considered the gold standard in surgical skills training and adjunctive learning modalities, such as sawbones and simulators, are used primarily to augment invaluable operating room experiences $[19,20]$. Nevertheless, we anticipate opportunities in the near future to pressure-test, standardize, and package pieces of the orthopaedic and sports curricula to supplement and reinforce current sports trainee education.

Despite the reduction in work hours and case volume, fellows and fellowship directors were only slightly concerned that COVID-19 would impact fellow readiness to start practice after graduation. Nearly, all fellowship directors expected their fellows to be prepared to graduate if elective cases resumed by June. Notably, however, $37.5 \%$ of fellow voiced concerns regarding their preparedness to their fellowship directors and $35 \%$ of fellowship directors reported hearing similar concerns from their fellows. The disconnect in concern voiced by the fellows and the assurance offered by the fellowship directors is likely due to the fact that many residents and fellows seek to gain their surgical self-confidence through experience and case volume [21]. Knowing that much of the sports literature promotes an association between surgeon volume and patient outcomes [22,23], many fellows may feel the need to prove their surgical skills to themselves prior to entering independent practice. Fellowship directors, on the other hand, maybe more focused on the demonstration of core competencies as criteria for graduating their fellows. Regardless, the consequence of COVID-19 on decreased case volume raises the question of whether a competency-based education model may be more effective than the current time-based training model for orthopaedic residents and sports fellows.

The current model for surgical training was established in 1889 by Dr. William Halstead and has remained relatively unchanged [24]. In the past decade, the academic orthopaedic community slowly began to introduce the concept of competency-based education [25]. The American Board of Orthopaedic Surgery, in cooperation with the Accreditation Council for Graduate Medical Education (ACGME), launched an initiative aimed at defining and assessing the essential clinical, surgical, and professional skills necessary for orthopaedic surgery residents to function as independent orthopaedic surgeons [26]. Despite the wellintentioned proposal, adoption of a competency-based orthopaedic education has been slow and met with resistance, owing primarily to the difficulty of standardizing assessments and the need for "buy-in" from all academic faculty [27]. We propose the impact of COVID-19 on sports surgery training highlights the importance of transitioning orthopaedic and sports fellow training to a robust competency-based model that ensures each fellow graduates with the clinical acumen and surgical skill set necessary to confidently pursue their professional orthopaedic practice.

Lastly, we identified that current sports surgery fellows are anxious about the current job market and future employment opportunities. At the time of this survey, $85.4 \%$ of sports fellows had at least received an offer letter or verbally committed to a job. However, widespread financial uncertainty across health care systems has led to furloughs [28] and hiring-freezes [29], leading more than half of sports fellows to be at least somewhat concerned about their future employment status. Although the job market of orthopaedic surgeons has historically been strong [30], only time will tell how this unprecedented crisis will affect employment success.

This survey-based study was not without limitations. First, although on par with expectations for an external survey, response rates were relatively low, representing $23.7 \%$ and $32.3 \%$ of all surveyed AOSSM fellows and fellowship directors, respectively. Low survey response rates may introduce biases that influence our ability to draw generalizable conclusions for all sports fellowship programs. Second, this survey was focused primarily on fellows' preparedness to perform surgically in the operating room. The effect of COVID-19 on the outpatient clinical experience was excluded from this study. Next, we assessed the impact 
of COVID-19 on fellow work hours; however, the survey did not delineate exactly how fellows were spending their time (i.e., non-sports surgery patient care, research, other orthopaedic services, etc.). Lastly, the survey reports subjective data regarding clinical and surgical aptitude and did not directly measure the effects of the COVID-19 pandemic on clinical or surgical proficiency. Nevertheless, we believe the results of this survey provide meaningful insight into the impact of COVID-19 on sports fellowship training, the selfperceived readiness of current sports fellows to enter practice after graduation, and the opportunity to improve sports surgery education and training in the post-pandemic era.

\section{Conclusions}

The impact of COVID-19 on health care systems across the world has been unprecedented. For sports surgery fellows, COVID-19 has directly affected work hours, case volume, case mix, and in-person education opportunities. Despite these specific challenges, sports fellows generally expect to be ready to enter practice after graduation, and their expectation is supported by the assurance of their fellowship directors. This survey also serves to highlight potential opportunities for innovation in online education and improvement in the sports fellowship education model.

\section{Additional Information \\ Disclosures}

Human subjects: Consent was obtained or waived by all participants in this study. Animal subjects: All authors have confirmed that this study did not involve animal subjects or tissue. Conflicts of interest: In compliance with the ICMJE uniform disclosure form, all authors declare the following: Payment/services info: All authors have declared that no financial support was received from any organization for the submitted work. Financial relationships: All authors have declared that they have no financial relationships at present or within the previous three years with any organizations that might have an interest in the submitted work. Other relationships: All authors have declared that there are no other relationships or activities that could appear to have influenced the submitted work.

\section{References}

1. Munster VJ, Koopmans M, van Doremalen N, van Riel D, de Wit E: A novel coronavirus emerging in China key questions for impact assessment. N Engl J Med. 2020, 382:692-694. 10.1056/NEJMp2000929

2. Barr J, Podolsky SH: A national medical response to crisis - the legacy of World War II . N Engl J Med. 2020, 383:613-615. 10.1056/NEJMp2008512

3. Ranney ML, Griffeth V, Jha AK: Critical supply shortages - the need for ventilators and personal protective equipment during the Covid-19 pandemic. N Engl J Med. 2020, 382:e41. 10.1056/NEJMp2006141

4. Characteristics of health care personnel with COVID-19 - United States, February 12 - April 9, 2020 . (2020). Accessed: October 20, 2020: https://www.cdc.gov/mmwr/volumes/69/wr/mm6915e6.htm.

5. AAOS: navigating the COVID-19 pandemic . (2020). Accessed: October 20, 2020: https://www.aaos.org/globalassets/about/covid-19/aaos-clinical-considerations-during-covid-19.pdf.

6. Stinner DJ, Lebrun C, Hsu JR, Jahangir AA, Mir HR: The orthopaedic trauma service and COVID-19: practice considerations to optimize outcomes and limit exposure. J Orthop Trauma. 2020, 34:333-340. 10.1097/BOT.0000000000001782

7. Reider B: Sports medicine in a time of pandemic . Am J Sports Med. 2020, 48:1303-1304. 10.1177/0363546520923334

8. Wright RW, Armstrong AD, Azar FM, et al.: The American Board of Orthopaedic Surgery response to COVID19. J Am Acad Orthop Surg. 2020, 28:e465-e468. 10.5435/jaaos-d-20-00392

9. Kogan M, Klein SE, Hannon CP, Nolte MT: Orthopaedic education during the COVID-19 pandemic . J Am Acad Orthop Surg. 2020, 28:e456-e464. 10.5435/JAAOS-D-20-00292

10. Horst PK, Choo K, Bharucha N, Vail TP: Graduates of orthopaedic residency training are increasingly subspecialized a review of the American Board of Orthopaedic Surgery part II database. J Bone Joint Surg Am. 2014, 97:869-875. 10.2106/JBJS.N.00995

11. Yin B, Gandhi J, Limpisvasti O, Mohr K, ElAttrache NS: Impact of fellowship training on clinical practice of orthopaedic sports medicine. J Bone Joint Surg Am. 2015, 97 :e27. 10.2106/JBJS.N.00164

12. O'Neill PJ, Cosgarea AJ, Freedman JA, Queale WS, McFarland EG: Arthroscopic proficiency: a survey of orthopaedic sports medicine fellowship directors and orthopaedic surgery department chairs. Arthroscopy. 2002, 18:795-800. 10.1053/jars.2002.31699

13. Jones J, Hunter D: Consensus methods for medical and health services research. Br Med J. 1995, 311:376380. 10.1136/bmj.311.7001.376

14. Census regions and divisions of the United States . (2010). Accessed: October 23, 2020: https://www2.census.gov/geo/pdfs/maps-data/maps/reference/us_regdiv.pdf.

15. Kilbourne ED: Influenza pandemics of the 20th century. Emerg Infect Dis. 2006, 12:9-14. 10.3201/eid1201.051254

16. Plancher KD, Shanmugam JP, Petterson SC: The changing face of orthopaedic education: searching for the new reality after COVID-19. Arthrosc Sports Med Rehabil. 2020, 2:e295-e298. 10.1016/j.asmr.2020.04.007

17. Dowdell JE, Louie PK, Virk S, et al.: Spine fellowship training reorganizing during a pandemic: perspectives from a tertiary orthopedic specialty center in the epicenter of outbreak. Spine J. 2020, 20:1381-1385. 10.1016/j.spinee.2020.04.015

18. Schwarzkopf R, Maher NA, Slover JD, Strauss EJ, Bosco JA, Zuckerman JD: The response of an orthopedic department and specialty hospital at the epicenter of a pandemic: the NYU Langone health experience. J Arthroplasty. 2020, 35:S3-S5. 10.1016/j.arth.2020.04.041 
19. Moulton CA, Dubrowski A, MacRae H, Graham B, Grober E, Reznick R: Teaching surgical skills: what kind of practice makes perfect?: a randomized, controlled trial. Ann Surg. 2006, 244:400-409.

10.1097/01.sla.0000234808.85789.6a

20. Vankipuram M, Kahol K, McLaren A, Panchanathan S: A virtual reality simulator for orthopedic basic skills: a design and validation study. J Biomed Inform. 2010, 43:661-668. 10.1016/j.jbi.2010.05.016

21. Blood TD, Gil JA, Born CT, Daniels AH: Variability in trauma case volume in orthopedic surgery residents . Orthop Rev (Pavia). 2017, 9:6967. 10.4081/or.2017.6967

22. Weinheimer KT, Smuin DM, Dhawan A: Patient outcomes as a function of shoulder surgeon volume: a systematic review. Arthroscopy. 2017, 33:1273-1281. 10.1016/j.arthro.2017.03.005

23. Schairer WW, Marx RG, Dempsey B, Ge Y, Lyman S: The relation between volume of ACL reconstruction and future knee surgery. Orthop J Sport Med. 2017, 5:2325967117S00298. 10.1177/2325967117s00298

24. Fritz T, Stachel N, Braun BJ: Evidence in surgical training - a review . Innov Surg Sci. 2019, 4:7-13. 10.1515/iss-2018-0026

25. Pellegrini VD, Ferguson PC, Cruess R, Cruess S, Briggs TW: Sufficient competence to enter the unsupervised practice of orthopaedics: what is it, when does it occur, and do we know it when we see it? J Bone Joint Surg Am. 2015, 97:1459-1464. 10.2106/JBJS.0.00025

26. Nousiainen M, Incoll I, Peabody T, Marsh JL: Can we agree on expectations and assessments of graduating residents?. J Bone Joint Surg Am. 2017, 99:e56. 10.2106/JBJS.16.01048

27. Ames SE, Ponce BA, Marsh JL, Hamstra SJ: Orthopaedic surgery residency milestones: initial formulation and future directions. J Am Acad Orthop Surg. 2020, 28:e1-e8. 10.5435/JAAOS-D-18-00786

28. Anoushiravani AA, O’Connor CM, DiCaprio MR, Iorio R: Economic impacts of the COVID-19 crisis . J Bone Joint Surg Am. 2020, 102:937-941. 10.2106/jbjs.20.00557

29. Stryker, Zimmer Biomet and more: how 12 device companies are controlling costs during COVID-19 . (2020). Accessed: October 20, 2020: https://www.beckersspine.com/orthopedic-a-spine-device-a-implantnews/item/48787-stryker-zimmer-biomet-more-how-8-dev....

30. Orthopaedic job market is changing. (2014). Accessed: October 23, 2020: https://www5.aaos.org/News/The_Daily_Edition_of_AAOS_Now/2014/Tuesday,_March_11/AAOS4_3_11/. 